\title{
Morfologia flexional dos verbos no Português Brasileiro e no Crioulo Haitiano
}

\author{
Lovania Roehrig Teixeira* \\ UFMS \\ Susiele Machry da Silva** \\ UTFPR
}

Recebido em: 24/06/2019

Aceito em: 04/12/2019

\begin{abstract}
Resumo: Este artigo constitui-se de uma análise bibliográfica comparativa da morfologia flexional do Crioulo Haitiano $(\mathrm{CH})$ e do Português Brasileiro (PB). Parte-se do levantamento bibliográfico dos aspectos da morfologia verbal nas duas línguas e da análise e discussão de dados de escrita de nativos do $\mathrm{CH}$, coletados para ilustrar como estes fazem o emprego dos verbos no PB. Confirmando a hipótese de que, dada a diferença morfológica entre as duas línguas, haitianos tendem a encontrar dificuldades no emprego dos tempos verbais, flexão e concordância, as análises desenvolvidas permitiram observar na escrita dos aprendizes inadequações nas flexões em tempo, número e pessoa.
\end{abstract}

Palavras-chave: Morfologia flexional. Português Brasileiro. Crioulo Haitiano.

\begin{abstract}
This article presents a comparative bibliographic analysis of the inflexional morphology of Haitian Creole (HC) and Brazilian Portuguese (BP). We surveyed aspects of the verbal morphology of both languages, analyzed and discussed the written data collected from native speakers of $\mathrm{CH}$ in order to illustrate how they use verbs in BP. Confirming the hypothesis that, given the morphological difference between the two languages, Haitian speakers tend to face difficulties when using Portuguese verbal tenses, inflexion and agreement, the analysis we carried out showed inadequacies in their use of inflexion of tense, number, and person when writing.
\end{abstract}

Keywords: Inflectional morphology. Brazilian Portuguese. Haitian Creole.

Resumen: Este artículo presenta una análisis bibliográfica comparativa de la morfología flexional del Criollo Haitiano $(\mathrm{CH})$ y del Portugués Brasileño (PB). Se hace un levantamiento bibliográfico de los aspectos de la morfología verbal en las dos lenguas y del análisis y discusión de los datos de escrita recogidos con nativos del $\mathrm{CH}$. La intención es ilustrar como estos hacen el empleo de los verbos en PB. Por lo tanto, se confirmó la hipótesis de que, dada la diferencia morfológica entre las dos lenguas, haitianos tienden a encontrar dificultades en el empleo de los tiempos verbales, flexión y concordancia.

Palabras clave: Morfología flexional. Portugués brasileño. Creólo Haití. 


\section{Introdução}

O fluxo da emigração haitiana foi bastante intenso a partir do ano de 2010, quando a república do Haiti, país localizado na América Central, sofreu devastações resultantes de forças naturais. Desde então, os haitianos, movidos pela esperança de reconstruírem suas vidas, têm o Brasil como um dos seus principais destinos (entre 2011 e 2018 foram registrados cerca de 106,1 mil haitianos ${ }^{1}$ ). $\mathrm{O}$ ensino do português brasileiro (doravante, PB) para esse público tornou-se, nesse contexto, emergente e necessário, uma vez que constitui um dos fatores principais para a inserção do imigrante no mercado de trabalho e na sociedade brasileira em geral.

Ao considerar a tríplice relação indivíduo-língua-sociedade, o entendimento dos fatores relacionados aos usos linguísticos e às dimensões que medeiam a comunicação, mostram-se imprescindíveis. Para Benveniste (1976, p. 27), "é dentro da, e pela língua, que indivíduo e sociedade se determinam mutuamente”. Assim, sociedade e indivíduo ganham existência quando imersos em uma língua. Alckmin (2008, p. 26) reitera que “[...] a língua é a manifestação concreta da faculdade humana da linguagem, isto é, da faculdade humana de simbolizar. Sendo assim, é pelo exercício da linguagem, pela utilização da língua, que o homem constrói sua relação com a natureza e com os outros homens". Nesse entendimento, é evidente a necessidade de oportunizar o acesso à língua dominante nas práticas sociais, como uma forma de inserção do indivíduo na sociedade. São, portanto, necessários estudos e ações para o atendimento a políticas linguísticas que possam promover a prática do acolhimento a públicos migratórios como os haitianos.

No âmbito linguístico, já que diferentes regras operam nas diferentes línguas, pensar a recepção linguística a imigrantes, requer a compreensão dos sistemas linguísticos envolvidos, estabelecendo a relação entre a gramática da língua nativa do aprendiz e a gramática da língua-alvo, no que tange aos aspectos fonético-fonológicos, morfológicos, semânticos e sintáticos. Essas regras determinam como as unidades da língua: sons, palavras, frases, sentenças e cadeias de sentença podem ser combinados (cf. SPEARS, 2010). A comparação entre sistemas linguísticos diferentes permite que se faça

\footnotetext{
${ }^{1}$ Dados com base no relatório anual (2019) do Observatório das Migrações Internacionais - OBMigra. Revista Investigações, Recife, v. 32, n. 2, p. 370 - 395, Dezembro/2019
} 
um levantamento das possíveis dificuldades que o aprendiz enfrentará em contato com a língua-alvo e como sanar tais dificuldades nos cursos de português para estrangeiros.

Frente ao exposto, compreendendo tanto a emergência da oferta de acolhimento linguístico para haitianos, e outros imigrantes, quanto à necessidade de preparo e de estudo para esse fim, a proposta deste artigo é entender as diferenças quanto ao emprego da flexão verbal nas duas línguas, Crioulo Haitiano e Português Brasileiro, embasando esta reflexão no uso dos verbos na modalidade escrita do PB por esses imigrantes. Para tanto, o trabalho parte de um estudo bibliográfico de aspectos morfológicos, especificamente, relacionados à flexão verbal nas línguas em estudo. Para o PB, utilizamos os relevantes estudos de Câmara Jr. (2017) e Ilari e Basso (20o8), já para o CH, fazemos uso das considerações de Degraff (2007, 2008), Bourdeaux (2014), Bentolila (1987), Lefebvre (2006, 2015) e Valdman (1977, 1988). A etapa de levantamento de informações bibliográficas é seguida por um levantamento e análise qualitativa de dados de escrita coletados junto a imigrantes haitianos, a partir de atividades desenvolvidas em curso de $\mathrm{PB}$ para esse público ${ }^{2}$. Os dados coletados têm a intenção de embasar as discussões, fazendo o diagnóstico do emprego dos verbos e suas adequações em tempo, número e pessoa.

Os dados de escrita foram recolhidos a partir de atividades práticas desenvolvidas em aula, contemplando as formas verbais em expressões do presente, do passado e do futuro. Para isso, organizou-se um jogo de perguntas e respostas, em que o aprendiz deveria entrevistar a um colega e registrar, por escrito, a resposta dada a cada uma das perguntas. A resposta deveria contemplar uma pequena frase e o uso da forma verbal adequada ao contexto, como ilustram os exemplos a seguir:
O que você fez ontem?
R. 1: Ontem eu estava em aula.
R. 2: *Eu trabalhando ontem³.

\footnotetext{
2 O Curso "Português como língua adicional: fala, escrita e compreensão" trata-se de uma ação de extensão realizada na Universidade Tecnológica Federal do Paraná, no Câmpus Pato Branco, e atende alunos haitianos e outros estrangeiros que têm interesse em aprender português brasileiro. Os encontros são semanais e estrangeiros de diferentes nacionalidades e com diferentes interesses frequentam as aulas. No entanto, o público, em sua maioria, é de imigrantes haitianos.

${ }^{3} \mathrm{O}$ asterisco antes da sentença marca a sua agramaticalidade, ou seja, indica que essa sentença não pertence à gramática da língua analisada. "Gramática", grosso modo, é entendida aqui como um Revista Investigaçũes, Recife, v. 32, n. 2, p. 370 - 395, Dezembro/2019
} 
(2)
O que você vai fazer amanhã?
R. 1: Amanhã eu vou trabalhar.
R.2: *Eu trabalha amanhã.

Foram incluídas no jogo doze (12) questões, envolvendo mais diretamente o uso dos verbos "fazer", "gostar", "ter” e "estar". A pergunta procurava dar um direcionamento quanto à pessoa e ao tempo do verbo (passado, presente ou futuro) a serem empregados nas respostas, mas não eram dadas instruções sobre a flexão do verbo. Ao todo foram oito (8) participantes que realizaram a atividade, todos imigrantes haitianos do sexo masculino, com idade entre 20 e 45 anos, com conhecimento básico-intermediário do PB (essa classificação foi obtida com base nas informações sociais declaradas pelos participantes e não por algum teste de nivelamento). Ressaltamos que antes da realização da atividade, os alunos foram informados de que a atividade seria utilizada também para fins de pesquisa e que eles estavam sendo convidados a participar. Caso não aceitassem o uso dos seus dados, a atividade não seria recolhida para análise ${ }^{4}$. Foram priorizadas formas verbais mais presentes no cotidiano dos aprendizes.

Os dados recolhidos foram organizados, sem qualquer identificação do informante, sendo, conforme o exposto, neste estudo, utilizados somente com o propósito de embasar as discussões acerca da gramática e dos usos das formas verbais do $\mathrm{PB}$ por nativos do $\mathrm{CH}$, partindo do entendimento de que as duas línguas diferem quanto ao emprego da flexão do verbo por tempo, modo e pessoa. Portanto, utilizamos neste estudo um método descritivo de base qualitativa.

A escolha por trabalhar com a flexão verbal se deu devido às diferenças linguísticas das duas línguas quanto a esse aspecto. $\mathrm{O}$ verbo no $\mathrm{CH}$ tende a apresentar uma morfologia diferente da do verbo no PB, não fazendo, por exemplo, a flexão e a concordância, em pessoa e em número, interna ao vocábulo como observamos na sentença do CH: "Mwen (eu)/ Ou (tu) / Li (ele/ela) / Nou (nós) / Yo (eles) konnen

\footnotetext{
conceito que leva em conta um conjunto de regras para formação de estruturas em uma dada língua. Tal conceito não está relacionado diretamente às regras da Gramática Normativa.

${ }^{4}$ Este estudo faz parte de um projeto sobre Ensino do Português como Língua Adicional para Haitianos e possui apreciação do Comitê de Ética em Pesquisa. Os participantes assinaram um Termo de Consentimento Livre e Esclarecido.
}

Revista Investiggações, Recife, v. 32, n. 2, p. 370 - 395, Dezembro/2019 
Boukinét"; aqui o verbo "conhecer" permanece invariável, mesmo diante da mudança de sujeito. Adicionalmente, a conjugação é realizada de forma diferenciada da do PB, pois os falantes de $\mathrm{CH}$ utilizam-se de partículas colocadas em frente aos verbos para indicar o tempo da conjugação (cf. VALDMAN, 1988), como em "Boukinét te renmen Bouki" (Boukinét amou Bouki), em que "te" representa a anterioridade da ação expressa pelo verbo “renmen”. Nessa língua, portanto, a noção de tempo não é expressa na morfologia do verbo, sendo a partícula que indica o tempo, externa.

Dada à diferença da morfologia verbal nas duas línguas, sendo nesse aspecto a gramática do português diversa em relação à gramática do $\mathrm{CH}$, parte-se da hipótese de que haitianos apresentem dificuldades no emprego dos verbos, ao fazer a flexão em tempo, número e pessoa, principalmente. Assim, ao expressar ações de passado, futuro, por exemplo, o aprendiz poderá não fazer uso das desinências que indicam essas informações (de tempo/número/pessoa), usando formas como: “eu trabalho ontem”, “eu estuda amanhã". No intuito de apresentar uma análise comparativa das duas línguas, PB e $\mathrm{CH}$, quanto à morfologia dos verbos e testar as hipóteses quanto ao emprego dos verbos do $\mathrm{PB}$ por nativos do $\mathrm{CH}$, este artigo encontra-se organizado, a partir desta introdução, em três seções. A primeira apresenta o levantamento teórico acerca dos aspectos morfossintáticos dos verbos no $\mathrm{PB}$, com a subsequente comparação com os aspectos no $\mathrm{CH}$, na segunda seção. A terceira parte, por sua vez, traz o levantamento dos dados de escrita coletados, procurando ilustrar o emprego dos verbos do PB por haitianos. E, finalmente, as considerações finais são apresentadas.

\section{Aspectos morfossintáticos do verbo no PB}

Para o PB, nas Gramáticas Tradicionais (MAIA, 1995; LIMA, 2003; entre outras), o verbo, de modo geral, é classificado como tal mediante alguns critérios, entre os quais: (i) um critério semântico, em que verbos designam processos (ações, estados ou fenômenos); (ii) um critério morfológico, pelo qual se afirma que verbos aceitam flexão de pessoa, número, tempo, modo e voz; e (iii) um critério sintático, em que se diz que o verbo é o centro da declaração que se faz ou o elemento de ligação entre um nome e uma qualidade a ele atribuída. Nesta seção nos deteremos ao critério morfológico de 
análise dos verbos do $\mathrm{PB}$, isto é, analisaremos o verbo como vocábulo formado pela reunião de morfemas5.

Segundo Ilari e Basso (2008, p. 169), a morfologia do verbo pode ser definida como o conjunto de formas que um verbo pode assumir, por efeito da conjugação (isto é, combinando-se afixos e desinências que distinguem "modos" e "tempos", "pessoas" e "números"). Sendo assim, a morfologia do verbo trata-se do conjunto das formas que poderiam resultar da aplicação de desinências previstas na gramática da língua radical ${ }^{6}$ do verbo.

Especificamente, tratamos aqui da flexão do verbo do PB que se apresenta por meio de segmentos fônicos pospostos ao radical, ou sufixos, como exemplificam as formas: (1) escreverá = escrev (radical) + e (vogal temática) + rá (desinência indicativa do futuro no modo indicativo); (2) escreveríamos = escrev (radical) + e (vogal temática) + ría (desinência indicativa do futuro do pretérito no modo indicativo) + mos (desinência número/pessoa). A estrutura do verbo no $\mathrm{PB}$ compreende, dessa forma, o radical e as desinências modo-temporal e de número/pessoa. Esses sufixos flexionais, ou desinências, não devem ser confundidos com os sufixos derivacionais, que geram novas palavras, como em feliz-mente; feliz-idade; feliz-ardo; etc.

Segundo Câmara Jr. (2017, p. 81), na flexão "há obrigatoriedade e sistematização coerente", já que ela é imposta pela natureza da frase. Por exemplo, é a natureza da sentença "Eu __ Maria ontem" que exige o preenchimento da lacuna com um verbo na primeira pessoa do pretérito perfeito, e.g., "beijei".

Segundo Câmara Jr. (2017, p. 85), parafraseado abaixo, nos verbos do PB figuram duas noções diferentes que se completam para flexionar o vocábulo verbal:

(i) o tempo: que indica o momento da ocorrência do evento a que o verbo se refere (do ponto de vista do momento da comunicação) em adição à noção de

\footnotetext{
${ }^{5}$ Os morfemas são os elementos constitutivos dos vocábulos e, segundo Câmara Jr. (2017, p. 23), podem ser de duas naturezas: (i) "lexical" associa o morfema com uma coisa do mundo biossocial e recebe expressão na língua, e.g., "estrel-", de estrela, e "com-" de comer; os morfemas lexicais constituem o cerne do vocábulo e uma série aberta; (ii) "gramatical" que entra na configuração formal da gramática da língua, como $-a$, da classe nominal de estrela ou o -e-, indicativo da $2^{\text {a }}$ conjugação de comer; os morfemas gramaticais formam um sistema mais ou menos fechado e constituem a gramática de uma língua.

" Não se faz a distinção teórica entre "raiz" e "radical" neste artigo, porque estamos: (i) discutindo especificamente a morfologia flexional do PB; (ii) considerando equivalentes o conceito de raiz e de radical de primeiro grau (cf. Margotti; Margotti, 2009). Portanto, utilizamos somente o termo "radical".
}

Revista Investigações, Recife, v. 32, n. 2, p. 370 - 395, Dezembro/2019 
modo (indicativo, subjuntivo, imperativo) e de aspecto - somente para o tempo pretérito.

(ii) a pessoa gramatical do sujeito: informação posposta à noção de tempo e indica o número (singular ou plural) do sujeito.

Um aspecto a ser ressaltado em relação à morfologia verbal do $\mathrm{PB}$, que se origina do latim, é a distinção entre radical e tema. O tema é o radical ampliado por uma vogal, a vogal temática, que coloca esses verbos numa classe morfológica distinta: $1^{\underline{a}}$ conjugação (fal+a: falar; grit+a: gritar); $2^{\underline{a}}$ conjugação (com+e: comer; escrev+e: escrever); $3^{\underline{a}}$ conjugação (part+i: partir; fing+i: fingir).

Quanto à noção de modo e à sua oposição, "o subjuntivo, incluindo o imperativo, assinala uma tomada de posição subjetiva do falante em relação ao processo verbal comunicado. No indicativo não há essa 'assinalização” (CÂMARA JR., 2017, p. 99). Considere as sentenças abaixo:

(3) Talvez seja verdade [que ele morreu].

(4) É verdade [que ele morreu].

Em (3), o verbo "ser" no modo subjuntivo (em adição ao advérbio talvez) expressa dúvida em relação ao fato descrito na oração encaixada "ele morreu”. Em (4), por sua vez, o modo indicativo expressa a afirmação do fato, ou seja, não há dúvida quanto ao fato de ele ter morrido.

Quanto à noção gramatical de tempo, no modo indicativo temos:

O tempo presente que pode significar:

(i) presente canônico: "Eu almoço agora";

(ii) histórico: "Eu almoço todo dia na rua"; e

(iii) futuro: "Eu almoço contigo daqui a 3 dias".

O tempo pretérito pode ser:

(i) mais-que-perfeito: descreve um evento passado anterior a outro, como em "O marido mentiu para a polícia, mas a mulher dissera a verdade";

(ii) imperfeito: relacionado à noção de aspecto, ou seja, a de inconclusão do evento como em "Ele escrevia a carta, quando acabou a luz"; e 
(iii) perfeito: um evento iniciado e terminado no passado como em "Ele escreveu a carta ontem”.

O tempo futuro pode ser:

(i) do presente: "Partirei amanhã" - expressa uma ação futura ou posterior ao momento da fala.

(ii) do pretérito: expressão de irrealidade como em "Partiria amanhã, se fosse rico".

Quanto à noção de tempo no modo subjuntivo temos os três tempos:

(i) presente: expressa hipótese como em "Para passar, é necessário que tu estudes";

(ii) pretérito imperfeito: expressa possibilidade ou desejo de uma ação, condicionada à outra: "Se ele escrevesse uma carta, talvez ganhasse o sorteio";

(iii) futuro: expressa a possibilidade de acontecer um evento como em "Quando o rei descobrir a traição, estaremos mortos”.

O modo imperativo, conforme Câmara Jr. (2017, p. 102), "é um subjuntivo sem o elo da subordinação sintática. Por isso, confunde-se formalmente com ele no verbo negativo e [...] no afirmativo" como se observa na comparação das duas sentenças a seguir: "Estudem muito para a prova!" (imperativo afirmativo) versus "É necessário [que eles estudem muito para a prova]" (presente do subjuntivo).

Em suma, o verbo é um vocábulo flexional no PB constituído de duas noções gramaticais de tempo e de modo, de um lado, e de outro, de pessoa e de número. Essas noções são indicadas por duas desinências, ou sufixos flexionais: o sufixo modotemporal (SMT) e o sufixo número-pessoal (SNP). Na morfologia verbal do PB, temos então: o radical $(\mathrm{R})$ + a vogal temática (VT), formando o tema $(\mathrm{T})$, e os sufixos flexionais de modo-tempo e de número-pessoa. Tudo isso gera a fórmula em (5) abaixo (CÂMARA JR. 2017, p. 104):

(5) $\quad \mathrm{T}(\mathrm{R}+\mathrm{VT})+\mathrm{SF}(\mathrm{SMT}+\mathrm{SNP})$

A cumulação num único morfema das noções de tempo e modo determina os sufixos modo-temporais (SMT) expostos no Quadro 1 e os sufixos número-pessoais apresentados no Quadro 2. 


\begin{tabular}{|c|c|}
\hline \multicolumn{2}{|c|}{$\begin{array}{l}\text { Quadro 1: Sufixos Modo-Temporais (SMT) do PB } \\
\text { SMT }\end{array}$} \\
\hline \multicolumn{2}{|c|}{ Modo Indicativo } \\
\hline Presente & $\varnothing$ \\
\hline Pretérito Perfeito & $\varnothing$ \\
\hline Pretérito imperfeito & $\begin{array}{l}1^{\text {a }} \text { conjugação: } v a / v e \\
2^{\text {a }} \text { e } 3^{\text {a }} \text { conjugação: } a / e\end{array}$ \\
\hline Pretérito mais que perfeito & $\mathrm{ra} / \mathrm{re}$ \\
\hline Futuro do presente & re / rá \\
\hline Futuro do pretérito & ria / rie \\
\hline \multicolumn{2}{|c|}{ Modo Subjuntivo } \\
\hline Presente & 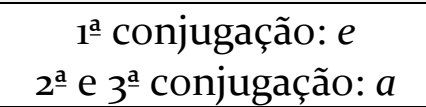 \\
\hline Pretérito Imperfeito & sse \\
\hline Futuro & $r$ \\
\hline
\end{tabular}

Fonte: os autores

\begin{tabular}{|l|c|}
\hline \multicolumn{2}{|c|}{$\begin{array}{c}\text { Quadro 2: Sufixos número-pessoais } \\
\text { (SNP) do PB } \\
\text { SNP }\end{array}$} \\
\hline $1^{\underline{a}}$ pes. singular & $i, \varnothing$, o \\
\hline $2^{\underline{a}}$ pes. singular & s, es, ste \\
\hline $3^{\underline{a}}$ pes. singular & $\emptyset, u$ \\
\hline $1^{\underline{a}}$ pes. plural & mos \\
\hline $2^{\underline{a}}$ pes. plural & is, des, stes \\
\hline $3^{\underline{a}}$ pes. plural & o, m, em, ram \\
& \\
\hline
\end{tabular}

Fonte: os autores

Na seção seguinte veremos as especificidades morfológicas dos verbos "ter", "gostar", "fazer" e "estar", mais recorrentes nos dados de escrita propostos no levantamento realizado por este estudo.

\subsection{Especificidades dos verbos 'ter', 'gostar', 'fazer' e 'estar' na gramática do PB}

A rica morfologia flexional dos verbos no $\mathrm{PB}$ faz com que falantes não-nativos tenham dificuldade no emprego das desinências indicativas de modo/tempo, número/pessoa, vistos serem estas não usuais em sua língua (no caso o $\mathrm{CH}$ ). Na fala de nativos, no input que recebem, os verbos podem ainda ser modificados, sofrendo variação. Usos como "nós come" e "tu come", omitindo as flexões de modo e tempo e de 
número e pessoa, são bastante comuns. Nesse sentido, além de entender os aspectos morfológicos da estrutura do verbo no $\mathrm{PB}$, como diferentes de sua língua, os não-nativos precisam entender as diferenças que ocorrem na fala de nativos por conta da variação.

Desse modo, as muitas informações gramaticais armazenadas no vocábulo verbal do PB consistem em uma das maiores dificuldades enfrentadas pelos estrangeiros, sobretudo falantes do $\mathrm{CH}$, no desenvolvimento da proficiência no PB. Além da complexa morfologia verbal do $\mathrm{PB}$, ocorre ainda que entre $\mathrm{CH}$ e $\mathrm{PB}$ há profundas diferenças morfológicas (detalhadas na seção 2 deste artigo).

Câmara Jr. (2017) ressalta, no trecho a seguir, que na morfologia do PB há uma complexidade, especificamente, pela acumulação de noções diferentes:

a complexidade para a interpretação do morfema flexional, propriamente verbal, em português, decorre, em primeiro lugar, da acumulação, que nele se faz, das noções de tempo e de modo, além da noção suplementar de aspecto que às vezes se inclui naquela primeira (CÂMARA JR, 2017, p. 98).

Além dos tipos de morfema citados por Câmara Jr. (2017), há ainda o morfema de pessoa e número que o autor não considera verbal por trazer informações da pessoa pronominal do sujeito, entendido como o ser de que parte o processo verbal.

Nesta seção, especificamente, tratamos da morfologia de alguns dos verbos que foram recorrentes nos dados dos aprendizes e falantes nativos do $\mathrm{CH}$, quais sejam, "ter", "gostar", "fazer" e "estar". Nesse conjunto de verbos, temos dois de primeira conjugação (estar e gostar) e dois de segunda conjugação (ter e fazer). Desses verbos, os verbos "ter", "estar" e "fazer" são verbos de conjugação irregular e o verbo "gostar" é considerado regular7.

Os verbos irregulares são aqueles que não acompanham o paradigma de determinada conjugação ( 1 aㅗ conjugação: vogal temática ' $a$ '; $2^{\text {a }}$ conjugação: vogal temática

$7 \mathrm{O}$ fato de termos analisado mais diretamente quatro verbos e desses, três serem irregulares, certamente geraria grande impacto em resultados de uma pesquisa quantitativa. No entanto, como estamos realizando uma pesquisa qualitativa esse impacto é mitigado, já que os objetivos deste artigo envolvem verificar o teor (e não o número/quantidade) das inadequações encontradas nos dados dos falantes de $\mathrm{CH}$ e se essas estão relacionadas às diferenças morfológicas dos verbos do $\mathrm{CH}$ e do PB. Salienta-se ainda que além desses, na escrita os informantes utilizaram outros verbos, como: falar, trabalhar, escrever, pegar, ir, entre outros.

Revista Investigaç̃̃es, Recife, v. 32, n. 2, p. 370 - 395, Dezembro/2019 
' $e$ '; $3^{\text {a }}$ conjugação: vogal temática 'i'), enquanto os verbos regulares acompanham o paradigma de sua conjugação e seu radical é invariável.

Os verbos irregulares são assim classificados por duas razões: (i) o sufixo flexional não segue o paradigma da conjugação, e.g., verbo "crer" na segunda pessoa do plural, “credes”, do presente do indicativo; (ii) ocorre alteração no radical, e.g., verbo "fazer" na primeira pessoa do singular, "faço", do presente do indicativo.

Dentre os verbos irregulares que estamos analisando, o verbo "fazer" é um verbo irregular porque apresenta mudanças em seu radical 'faz-' como em 'faço', 'fizeste', 'faria', etc. Os verbos "ter" e "estar”, por sua vez, são irregulares por não seguirem o paradigma verbal de suas conjugações (a $1^{\underline{a}}$ e a $\left.2^{\underline{a}}\right)$, i.e., seus sufixos de número-pessoa e de modotempo não seguem a padrão das conjugações. O verbo "gostar" é um verbo regular que segue o paradigma verbal de sua conjugação. Podemos observar esses aspectos apontados, no quadro a seguir:

Quadro 3: Conjugação dos verbos no PB - regulares e irregulares

\begin{tabular}{|l|l|l|l|l|l|l|}
\hline \multicolumn{7}{|c|}{ Presente Indicativo } \\
\hline gostar & gost -o & gost -as & gost -a & gost -amos & gost -ais & gost -am \\
\hline estar & est -ou & est -ás & est -á & est -amos & est -ais & est -ão \\
\hline ter & $\mathbf{t}$-enho & $\mathbf{t}$-ens & $\mathbf{t}$-em & $\mathbf{t}$-emos & t -ens & t -êm \\
\hline fazer & faç -o & faz -es & faz - $\boldsymbol{\emptyset}$ & faz -emos & faz -eis & faz -em \\
\hline
\end{tabular}

Fonte: os autores

Pelo exposto, podemos afirmar que, além da rica morfologia flexional dos verbos do PB, uma das dificuldades adicionais para o alcance da proficiência na língua-alvo pelos falantes de outras línguas, como é o caso dos nativos do $\mathrm{CH}$, é a existência de um grande número de verbos irregulares como os verbos "estar", "ter" e "fazer", os quais são produtivamente usados nas interações cotidianas em PB. Portanto, além de adquirir noções das marcas morfológicas da flexão do verbo no PB quanto ao modo, tempo e pessoa, por exemplo, os aprendizes haitianos terão de entender possíveis mudanças na regularidade do verbo.

2 Crioulo Haitiano: aspectos gramaticais morfossintáticos 
O CH é uma língua falada no Haiti por nove milhões de pessoas em média. O idioma é reconhecido como língua oficial desse país, mas tem se espalhado por outros países como Estados Unidos, Canadá, Brasil, entre outros, nos frequentes movimentos migratórios (cf. SPEARS, 2010). Além do $\mathrm{CH}$, no Haiti também são faladas, por boa parte da população, línguas como o francês e o inglês ${ }^{8}$. Spears (2010) ressalta que o CH não é uma forma alterada do francês, embora por muitas vezes tenha sido erroneamente assim entendido. Segundo o autor, o CH é uma língua independente do francês e com uma gramática própria.

Spears (2010) esclarece que o francês e CH apresentam semelhanças em muitas formas lexicais e até mesmo fonológicas, mas são línguas distintas no nível morfossintático. Uma das salientes diferenças entre essas línguas situa-se nas formas verbais: o $\mathrm{CH}$ não apresenta morfologia flexional. No entanto, no francês (do mesmo modo que no $\mathrm{PB}$ ) se expressa o tempo no próprio verbo, com auxílio de morfemas.

Agora comparando o PB com $\mathrm{CH}$, observa-se que a organização distribucional (sintática) do $\mathrm{CH}$ é similar a do $\mathrm{PB}$, visto que as duas línguas estruturam as sentenças seguindo a sequência Sujeito - Verbo - Objeto, ambas, portanto, são línguas SVO. Não obstante, o CH é uma língua SVO que não apresenta morfologia flexional.

$\mathrm{O} \mathrm{CH}$, se novamente comparado ao $\mathrm{PB}$, parece seguir a mesma estrutura argumental e temática dos verbos. Considere o exemplo de Degraff (p. 300, 2008):

(6) Bouki konnen Boukinét.

Bouki conhecer Boukinét

'Bouki conhece Boukinét'

Observamos que o verbo 'konnen' do $\mathrm{CH}$ exige dois argumentos um "indivíduo conhecedor" e outro "indivíduo a ser conhecido" e atribuem, por isso, dois

\footnotetext{
${ }^{8}$ No grupo investigado, todos os participantes tinham o $\mathrm{CH}$ como língua nativa, dois deles afirmaram ter o francês como segunda língua e apenas um informou ter conhecimento do inglês (dados coletados nas informações sociais preenchidas por cada informante).

Revista Investigações, Recife, v. 32, n. 2, p. 370 - 395, Dezembro/2019
} 
papéis temáticos, o de experienciador e o de tema ${ }^{9}$, do mesmo modo que o verbo “conhecer” do PB em 'Maria conhece João'.

No entanto, uma diferença distribucional em relação ao PB é a colocação dos objetos pronominais e não pronominais. No $\mathrm{CH}$, esses elementos sempre aparecem após o verbo, observe o exemplo (7) em que isso acontece. Note, contudo, a agramaticalidade do exemplo (8) em que o objeto está anteposto ao verbo. Enquanto que, no $\mathrm{PB}$, os pronomes podem aparecer, teoricamente, em três posições em relação ao verbo: ênclise: posposto ao verbo, e.g., conheci-a; mesóclise: no meio do verbo, e.g., conhecer-te-ia; e a próclise: anteposto ao verbo, e.g., a conheci.

(7) Bouki konnen li

Bouki conhecer 3 sg

'Bouki conhece -a/o'

(8) *Bouki li konnen

Bouki 3sg conhecer

'Bouki a/o conhece'

Com base em Degraff (2007, 2008), a estrutura argumental e temática do verbo no $\mathrm{CH}$ é semelhante à do francês, a exemplo da forma verbal konnen (conhecer), com propriedades léxico-semânticas similares a connaître, do francês. Isto é, em ambas as línguas o verbo exige o mesmo número de argumentos (dois, tanto para konnen $(\mathrm{CH})$ quanto para connaître (francês)). Essa semelhança com o francês é observada em outros itens lexicais do $\mathrm{CH}$, mas, de acordo com o autor, existe uma robusta diferença morfossintática entre as duas línguas. Uma delas está relacionada à distribuição dos objetos pronominais e não pronominais que, como vimos acima, em (7), sempre aparecem pospostos ao verbo no $\mathrm{CH}$. No entanto, no francês, os objetos pronominais podem aparecer antepostos ao verbo, como na sentença abaixo.

(9) Bouqui la connaît.

${ }^{9}$ Direcionamos o leitor interessado na classificação pormenorizada dos papéis temáticos a Parsons (1995). 
Bouqui 3sg-fem conhecer

'Bouqui a conhece'

Outra diferença em relação ao francês, segundo Degraff (2008), está relacionada à flexão dos verbos. Esse elemento no $\mathrm{CH}$ não possui marcas morfológicas de aspecto, tempo, modo, ou pessoa (DEGRAFF, 20o8, p. 301). Isso mostra que, o $\mathrm{CH}$ possui uma morfologia flexional diferente da do PB também, já que nesta língua o verbo apresenta desinências de modo e tempo e de número e pessoa, respectivamente (como apontado na seção 1). Observe o exemplo a seguir (cf. Degraff, 2008, p. 302) em que verificamos que o verbo permanece invariável apesar da mudança de sujeitos:

(10) [ Mwen / Ou / Li / Nou / Yo] konnen Boukinét.

1sg/ 2sg/ 3sg/ 1pl/ 2pl/ 3pl conhecer Boukinét

'[Eu / tu/ ele/ela / nós /eles] conhece Boukinét'

Segundo Degraff (2008, p. 302), tempo, modo e aspecto são expressos no $\mathrm{CH}$ por morfemas livres, ou seja, partículas que funcionam de forma independente ao verbo, como mostram as sentenças em (11), abaixo:

(11) a.Boukinét te renmen Bouki.

Boukinét ANT amar Bouki

'Boukinét amou Bouki.'

b. Boukinét ap renmen Bouki.

Boukinét FUT amoar Bouki

'Boukinét amará Bouki.'

c. Boukinét a renmen Bouki si ...

Boukinét IRR amar Bouki se....

'Boukinét amaria Bouki se...' 
Antes de seguirmos com essa discussão, é importante apresentarmos as distinções entre morfema preso, dependente e livre. Segundo Câmara Jr. (2017, p. 6970), os vocábulos átonos que não constituem, por si só, um enunciado, ou seja, não possuem o status de palavra, são chamadas "formas ${ }^{10}$ dependentes", como as conjunções 'em', 'o', etc. Os vocábulos tônicos, por sua vez, possuem o status de palavra e são chamados de "formas livres". Esses são assim chamados, pois podem funcionar isoladamente como comunicação suficiente, como na resposta à questão "O que vocês vão fazer?" "Nada”. E ainda há as “formas presas, que só funcionam ligadas a outras (como pro- de proscrever, prometer, etc.)" (CÂMARA JR., 2017, p. 69).

Mantendo em mente esses conceitos, vimos que Degraff (2008) afirma que as partículas de tempo, modo e aspecto do $\mathrm{CH}$ são morfemas livres. É certo que tais partículas não são morfemas presos, pois não estão ligadas aos verbos. Mas surgem dúvidas quanto à classificação desses elementos em morfemas livres ou dependentes, pois os exemplos encontrados na literatura mostram as partículas sempre acompanhando os verbos. Desse modo, elas poderiam ser consideradas "morfemas dependentes". O teste mais adequado para verificar esse aspecto seria observar dados de fala do $\mathrm{CH}$ e verificar se elas funcionam como "comunicação suficiente" quando isoladas, no entanto esse aspecto está fora do escopo deste artigo. Feitas essas ressalvas, seguimos a classificação de Degraff (2008) denominando tais partículas de "morfemas independentes" ou “morfemas livres".

Nesses casos, vemos que os morfemas (te, ap, a) do $\mathrm{CH}$ são formas lexicalizadas, independentes do verbo, (renmen) e se colocam à frente dele para descrever que o evento de "amar" aconteceu no passado (ANT = anterior), acontecerá no futuro (FUT = futuro) e o evento de 'amar' é ainda uma hipótese (IRR = irreal ou subjuntivo). Desse modo, os verbos do $\mathrm{CH}$, diferentemente do $\mathrm{PB}$, não possuem desinências de modo e tempo, nem de pessoa e número. Além disso, somente tempo, modo e aspecto são marcados por morfemas livres.

Em outras palavras, as informações de aspecto, modo e tempo, são dadas no $\mathrm{CH}$ por meio de partículas pré-verbais, morfemas livres, localizadas entre o pronome e o verbo. Dessa forma, as construções verbais seguem uma regularidade, como

\footnotetext{
${ }^{10}$ Aqui, não faremos distinção entre "forma" e "morfema", usando-os como sinônimos.

Revista Investigações, Recife, v. 32, n. 2, p. 370 - 395, Dezembro/2019
} 
exemplificado ao conjugar o verbo "pale” em tempo presente - falar: 'm pale' (eu falo), 'nou pale' (nós falamos), 'li pale' (ele fala). Vemos que o vocábulo verbal permanece inalterado, alterando apenas a forma pronominal. No passado simples, o verbo permanece inalterado, a mudança fica por conta do acréscimo da partícula 'te', como em: ' $m$ te pale' (eu falei); 'li te pale' (ele falou).

Abaixo apresentamos o Quadro 4 com um inventário dos morfemas livres de tempo, modo e aspecto do CH (cf. LEFEBVRE, 2015, p. 340):

Quadro 4: Morfemas livres de tempo, modo, aspecto do $\mathrm{CH}$

\begin{tabular}{|c|r|r|r|}
\hline $\begin{array}{r}\text { IRREALIS } \\
\text { Subjuntivo }\end{array}$ & $\begin{array}{r}\text { ANTERIOR } \\
\text { Passado }\end{array}$ & FUTURO & $\begin{array}{r}\text { INCOMPLETA } \\
\text { Imperfectivo }\end{array}$ \\
\hline \multirow{2}{*}{ pou } & \multirow{2}{*}{ te } & Futuro & \\
& & $a p$ & $a p$ \\
& & Futuro & \\
& & indefinido & \\
& & $a-v a$ & \\
\hline
\end{tabular}

Fonte: LEFEBVRE, 2015, p. 340

Segundo Lefebvre (2006),

As marcas de futuro definido são usadas para veicular a atitude do falante de que o evento referido na oração definitivamente ocorrerá em um futuro próximo. Por contraste, as marcas de futuro indefinido são usadas para indicar a opinião do falante de que o evento referido pela oração poderá, eventualmente ou potencialmente, ocorrer em um ponto indeterminado do futuro (LEFEBVRE, 2006, p. 112. Tradução nossa" ${ }^{11}$.

Além disso, segundo Lefebvre (2006, p. 112) o morfema 'ap', que é marca do futuro, e 'ap', que é marca do imperfectivo, são palavras homófonas. Ainda, conforme o autor,

\footnotetext{
11 The definite future markers are used to convey the speaker's attitude that the event referred to by the clause will definitely take place in the near future. By contrast, the indefinite future markers are used to convey the speaker's opinion that the event referred to by the clause might eventually or potentially take place at an undetermined point in the future.

Revista Investigações, Recife, v. 32, n. 2, p. 370 - 395, Dezembro/2019
} 
há duas entradas lexicais separadas no léxico do $\mathrm{CH}$ para cada um dos itens. Prova disso é que é possível utilizar duas vezes a palavra 'ap’ em uma única oração como em:

(12) M' ap ap sòti.

Eu DEF-FUT IMP sair

'Eu estarei saindo'.

No entanto, há casos em que

Pode haver sentenças nuas, isto é, sentenças que não contenham expressão explícita de tempo, modo ou aspecto; nesses casos a interpretação temporal é calculada por vários componentes que participam no estabelecimento da propriedade aspectual da oração (LEFEBVRE, 2015, p. 338. Tradução nossa ${ }^{12}$ ).

Desse modo, no $\mathrm{CH}$ há sentenças que podem não ter morfemas pré-verbais indicando o tempo, o modo ou o aspecto. Considere o exemplo (13) retirado de Lefebvre (2006, p.114):

(13) Mari kònnèn Jan.

Mary conhecer John

'Mary conhece John'.

A possibilidade de sentenças sem marca de tempo, modo, aspecto no $\mathrm{CH}$ contrasta com a impossibilidade dessas sentenças ocorrerem no PB. No PB, cada oração deve ser marcada para modo (indicativo, imperativo ou subjuntivo) e cada oração marcada temporalmente carrega morfologicamente o tempo (presente, passado ou futuro).

Ainda, segundo Lefebvre (2006, 2015), a interpretação das sentenças sem marca de tempo no $\mathrm{CH}$ é computada a partir da interação de diferentes componentes que participam do estabelecimento das propriedades aspectuais de uma oração, tais como: a classe aspectual do verbo, a definitude do objeto direto e a definitude do sujeito.

12 There can be bare sentences, that is, sentences containing no overt expression of Tense, Mood or Aspect; in this case the temporal interpretation of the clause is computed from the various components that participate in establishing the aspectual properties of a clause.

Revista Investigações, Recife, v. 32, n. 2, p. 370 - 395, Dezembro/2019 
Sobre os componentes essenciais para a interpretação das sentenças sem marcas pré-verbais de tempo é importante saber que no $\mathrm{CH}$ há três classes acionais do verbo, constituídas por: (i) verbos dinâmicos, relacionados a algo em andamento, dando ideia de continuidade, e.g., 'manje' (comer) e 'plante' (plantar); (ii) verbos resultativos ${ }^{13}$, descrevem a situação resultado de algum processo, e.g., 'jwenn' (encontrar); e (iii) verbos estativos, aqueles que não indicam uma ação, e.g., 'kònnèn' (conhecer) e 'bezwèn' (precisar) (cf. BOUDREAUX, 2014). Além disso, um sintagma nominal (objeto ou sujeito) para ser considerado definido no $\mathrm{CH}$ deve ter um determinante pós-nominal como 'la' ou seus alomorfes 'a', 'na', 'nan'.

Por exemplo, uma sentença atemporal do $\mathrm{CH}$ contendo um verbo dinâmico com um objeto definido só pode ser interpretada como passado, segundo Lefebvre (2006, p 134):

(14) Maria prepare pat la.

Maria preparar massa DET.

'Maria preparou a massa'.

Uma sentença atemporal com um verbo dinâmico e um objeto indefinido é ambígua entre uma interpretação de presente ou de passado (LEFEBVRE, 2006, p. 134):

(15) Maria prepare pat.

Maria preparar massa.

a. 'Maria prepara massa (geralmente)'.

b. 'Maria preparou massa'.

A definitude do sujeito também tem consequências sobre a interpretação das sentenças atemporais do CH. Compare os exemplos abaixo de Bentolila (1987): (16) com sujeito definido e (17) com sujeito genérico.

(16) Mayi a ba nou bon garanti.

${ }^{13}$ Os verbos resultativos são os verbos como 'fazer', 'construir', 'organizar', 'acarretar' e 'provocar' que são caracterizados por terem um objeto como resultado da ação verbal.

Revista Investigações, Recife, v. 32, n. 2, p. 370 - 395, Dezembro/2019 
Milho DET dar nos bom lucro

'O milho tem nos dado bons lucros'.

(17) Mayi ba nou bon garanti.

Milho dar nos bom lucro

'Milho (geralmente) nos dá bons lucros'.

Aqui a linha que diferencia a interpretação de (16) e de (17) é tênue; aparentemente, no uso do sujeito definido (16) os lucros são atuais (resultado presente); já no sujeito genérico (17) os lucros podem não ser uma realidade atual, nem certa.

Outra característica que diferencia os aspectos morfossintáticos do $\mathrm{CH}$ em relação ao PB está no uso das preposições entre verbo e objeto indireto. No PB, de acordo com a regência do verbo há, ou não, necessidade da preposição. Assim, a exemplo, casos de verbos como 'gostar', 'chegar', com transitividade indireta, exigem o uso da preposição; enquanto outros como 'comer', 'esperar', não possuem tal exigência.

No $\mathrm{CH}$, a transitividade verbal é diferente da do $\mathrm{PB}$, não havendo o uso de preposições. Nessa língua são mais comuns formas com sequências de mais de um verbo, a exemplo de um verbo de direção + verbo principal como 'vini pote' (venha trazer) ou de verbo principal + verbo principal como "pral manje" (irei comer) (cf. VALDMAN, 1988).

Além dessas características, o $\mathrm{CH}$, diferentemente do $\mathrm{PB}$, não possui verbos irregulares. Na língua, verbos como 'ser' e 'estar', por exemplo, são expressos pelas formas 'se' e 'ye', nas diferentes formas pronominais, como em: (1) 'Se yon plim' (é uma caneta); (2) 'M' se yon militat' (sou um militar); (3) 'Nou se zanmi' (nós somos amigos).

A partir do exposto comparativo, notamos que o falante nativo do $\mathrm{CH}$ em contato com o PB está, no que se refere ao uso de verbos, diante de uma gramática diferente daquela de sua língua, necessitando observar parâmetros tais como: a) conjugação e flexão dos verbos, não comuns na sua língua; b) flexão do verbo de acordo com número, pessoa; (c) uso de preposições de acordo com a regência do verbo; (d) mudança de radicais em verbos irregulares. Essas diferenças gramaticais devem ser assimiladas pelos imigrantes haitianos para o desenvolvimento da sua gramática na nova língua, no caso 
o PB, somando-se a outras dificuldades decorrentes das diferenças socioculturais entre Haiti e Brasil.

\section{$3 \mathrm{O}$ emprego de verbos do $\mathrm{PB}$ por nativos do $\mathrm{CH}$}

O uso adequado dos morfemas flexionais dos verbos no PB é uma atividade complexa até mesmo para os falantes nativos. No entanto, quando se compara o sistema flexional do $\mathrm{CH}$ com o do $\mathrm{PB}$, entende-se que as dificuldades a serem enfrentadas pelos aprendizes haitianos são multiplicadas, principalmente porque o PB possui um sistema flexional rico, se comparado ao sistema do $\mathrm{CH}$. Em consequência, os aprendizes, no processo de aprendizagem da língua-objeto, produzem construções inadequadas. Fato esperado, afinal, para que ocorra a construção da gramática da nova língua há um profundo processo de reorganização em relação aos parâmetros da língua-mãe, principalmente, tendo em vista as diferenças morfológicas entre a língua nativa do aprendiz e a língua-objeto.

Partindo desse entendimento acerca das diferenças entre a gramática do aprendiz, no caso o $\mathrm{CH}$, e a gramática do $\mathrm{PB}$, foi observado o emprego dos verbos na escrita do PB por nativos haitianos residentes no Brasil, aprendizes dessa língua. Ao ser contatado, o informante, se de acordo, respondia a um questionário com informações sociais, sobre: tempo de residência no Brasil, conhecimento de outras línguas e autodeclaração sobre o tempo de uso, tempo de curso e proficiência na fala, leitura e escrita do português. O tempo de residência destes informantes variava entre 6 meses, tempo mínimo pré-estabelecido, e cinco anos. Todos os participantes, no momento da pesquisa, frequentavam o curso "Português como língua adicional: fala, escrita e compreensão” na Universidade Tecnológica Federal do Paraná, no Campus Pato Branco.

A atividade, como exposto na seção introdutória, contemplava um exercício de perguntas e respostas, incitando o uso de formas verbais do indicativo, nos tempos presente passado e futuro, na construção de respostas afirmativas ou negativas. Como já mencionado, buscou-se contemplar as formas verbais usuais nas interações cotidianas dos aprendizes, no entendimento de serem estas mais familiares e necessárias aos informantes. Realizou-se um levantamento inicial das produções com verbos dos 
informantes nos tempos presente, passado e futuro. Ao todo, foram obtidos 84 dados ${ }^{14}$ com emprego de verbos; esses dados encontram-se descritos na Figura 1, que ilustra os casos de adequação ou não-adequação quanto às flexões modo/tempo e número/pessoa.

Figura 1: Gráfico ilustrativo do emprego dos verbos

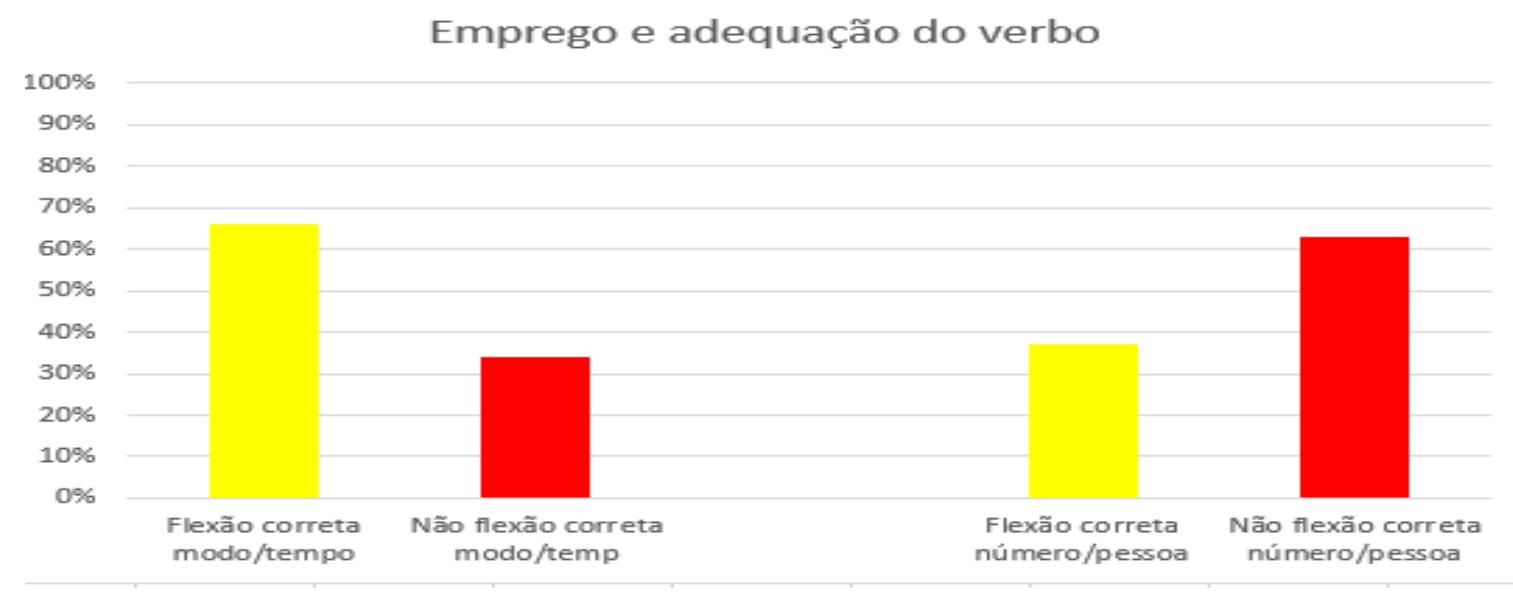

Fonte: os autores

Conforme expressam os dados descritos no Gráfico, em 66\% dos casos, os informantes realizam a correta adequação do verbo de acordo com modo/tempo e, em $37 \%$ dos casos, fazem a correta flexão número/pessoa. Tais dados revelam que o uso da flexão número/pessoa teve mais inadequações, e por isso, é uma atividade mais complexa para os aprendizes, se comparada à expressão das ações em tempo presente, passado e futuro. As ações verbais do presente foram adequadamente expressas pelos informantes na maior parte das ocorrências (com 84\% de acertos), seguidas pelas formas verbais de futuro (com $64 \%$ de acertos) e de passado ( $57 \%$ de acertos).

Ao verificar os dados, observa-se que nas construções, o informante consegue, mesmo não fazendo o uso "correto" da forma verbal, expressar se a ação é presente, passado ou futuro, como nos exemplos: (1) Tem medo do [...]; (2) Eu foi na escola; (3) Vai na minha casa. Na informação do futuro, parece haver a preferência pelo uso das formas com verbo auxiliar + verbo principal, como nos exemplos: (1) eu vai pegar; (2) vai fazer aula. São poucas as formas em que a ação futura é expressa pela forma simples como

\footnotetext{
${ }^{14}$ Salienta-se que os dados coletados para este estudo tiveram a intenção de exemplificar o uso dos tempos verbais por imigrantes haitianos, priorizando uma análise qualitativa desses usos, de forma a embasar as discussões acerca das diferenças morfológicas entre a gramática da $L 1(\mathrm{CH})$ e a gramática da L2 (PB).
} 
"irei no supermercado" (apenas 02 dados na amostra realizam este emprego). Nas expressões de pretérito, predomina o uso de dois verbos, sendo a noção de passado expressa em um deles (ex.: eu acorda tomou café). O tempo presente é corretamente expresso, mas muitas vezes sem a flexão número/pessoa, exemplo: (1) “eu gosta música”; (2) "estou escreva".

Assim, na flexão número/pessoa, observa-se o uso de formas como: (1) eu gosta; (2) limpa a casa; (3) toma o banho; (3) aprende escrever. As perguntas direcionavam, em sua maioria, para o uso da primeira pessoa do singular, sendo para esses casos a forma preferida pelos participantes, foi o uso do infinitivo, ou com a terminação 'a' ou 'e' (limpo >> limpa; assisto >> assiste). Outra característica observada é o não emprego de preposição nos verbos que no PB possuem transitividade indireta (ex.: gostar, ir), como nos empregos: (1) "gosta problema”, (2) "não gosto cozinha”; (3) “fui igreja”; (4) "fui banho".

O Quadro 3, a seguir, ilustra alguns exemplos do emprego dos verbos na escrita de nativos do $\mathrm{CH}$, a partir das observações do (não-)adequado emprego da flexão de tempo do verbo, assim como do uso explícito ou não da informação de pessoa e número.

Quadro 5: Exemplificações a partir do emprego de formas verbais

\begin{tabular}{|c|c|c|}
\hline \multirow[t]{2}{*}{ Pergunta } & \multicolumn{2}{|c|}{ Exemplos } \\
\hline & $\begin{array}{c}\text { Construções adequadas quanto ao } \\
\text { tempo, à pessoa e ao número }\end{array}$ & $\begin{array}{c}\text { Não adequação ao tempo, à } \\
\text { pessoa, ou ao número }\end{array}$ \\
\hline $\begin{array}{l}\text { O que você fez } \\
\text { ontem? }\end{array}$ & $\begin{array}{l}\text { Eu falei com um amigo } \\
\text { Tani trabalhou ontem } \\
\text { Eu estava em aula }\end{array}$ & $\begin{array}{l}\text { *Eu não faz nada } \\
\text { *não faz nada } \\
\text { *Eu fez café da manhã } \\
\text { *trabalhando }\end{array}$ \\
\hline $\begin{array}{l}\text { O que você vai } \\
\text { fazer amanhã? }\end{array}$ & $\begin{array}{l}\text { Eu irei no supermercado. } \\
\text { Eu vou comer. } \\
\text { Vou jogar futebal. } \\
\text { Vou trabalha. }\end{array}$ & $\begin{array}{l}\text { *Eu vai fazer amanhã trabalhar } \\
\text { * Eu foi na escola } \\
\text { *Amanhã eu vai trabalhar } \\
\text { * Eu vou faço dormir }\end{array}$ \\
\hline $\begin{array}{l}\text { O que você faz } \\
\text { quando acorda? }\end{array}$ & *Eu vou ao banhiero. & $\begin{array}{l}\text { * Eu escovar meus dentes } \\
\text { * Eu vai toma o banho. } \\
\text { * Eu acorda toma de café. } \\
\text { * Quando eu acorda eu escova } \\
\text { meu dente. } \\
\text { * Quando acordo fui banho. } \\
\text { * Quando acorda levantou para } \\
\text { fui no banho. } \\
{ }^{*} \text { Escova os dentes. }\end{array}$ \\
\hline
\end{tabular}




\begin{tabular}{|c|c|c|}
\hline $\begin{array}{l}\text { O que você faz } \\
\text { antes de dormir? }\end{array}$ & $\begin{array}{l}\text { Antes de dormir, eu falo com meus } \\
\text { paes. } \\
\text { Eu falo com amigo. } \\
\text { Eu leio um livro. }\end{array}$ & $\begin{array}{l}\text { *Antes de dormir falou com } \\
\text { Deus. } \\
\text { * Falou com meu amigo família. } \\
\text { * Antes de dormir eu escuta } \\
\text { música. } \\
\text { * Antes de dormir eu rezar. } \\
\text { * Antes de dormir eu ficou na } \\
\text { meu telefone. } \\
\text { * Eu escova toma o banho }\end{array}$ \\
\hline $\begin{array}{l}\text { O que você faz } \\
\text { quando sai da } \\
\text { aula? }\end{array}$ & $\begin{array}{l}\text { Eu vou para minha casa. } \\
\text { Eu estudo. } \\
\text { Eu vou a meu apartamento } \\
\text { Quando sai da aula, eu janto. }\end{array}$ & $\begin{array}{l}\text { *Vai na minha casa. } \\
\text { * Quando eu sair da aula eu } \\
\text { volta na minha casa. } \\
\text { * Quando sai da aula vou } \\
\text { ônibus. } \\
{ }^{*} \text { Quando sai da aula vou pego } \\
\text { onnibus } \\
\text { * Eu jogar com minha } \\
\text { cacholinha. }\end{array}$ \\
\hline $\begin{array}{l}\text { Do que você não } \\
\text { gosta? } \\
\text { Do que você mais } \\
\text { gosta? }\end{array}$ & $\begin{array}{l}\text { Eu não gosto café } \\
\text { Eu não gosto de levantar cedo. } \\
\text { Eu gosto estudar. } \\
\text { Eu gosto música. } \\
\text { Eu não gosto brigar. } \\
\text { Eu não gosto café. }\end{array}$ & $\begin{array}{l}\text { * Eu mais gosta brugando. } \\
\text { * Eu mais gosta de futebol. } \\
\text { * Eu não gosta de problema } \\
\text { * Eu mais gosta brugando } \\
\text { * Eu gosta musca. }\end{array}$ \\
\hline $\begin{array}{l}\text { O que você faz no } \\
\text { final de semana? }\end{array}$ & $\begin{array}{l}\text { Eu faço comida. } \\
\text { Vou jogar futbol. } \\
\text { Eu estudo em minha casa. } \\
\text { A final de semana eu faço meu } \\
\text { dever. }\end{array}$ & $\begin{array}{l}\text { * No final de semana, eu fiz } \\
\text { coizas divertidas. } \\
\text { * No final de semana, eu fazer } \\
\text { muitos coisa. } \\
\text { * No final de semana fui na } \\
\text { egrija } \\
\text { * No final de semana, eu fiz } \\
\text { coizas divertidas. }\end{array}$ \\
\hline
\end{tabular}

Fonte: as autoras

Como podemos observar, o levantamento dos dados sugere dificuldades dos aprendizes em realizar a flexão do verbo de acordo com o tempo, a pessoa e o número. Nas construções com informação de passado, a partir da questão exemplificada como: “o que você fez ontem?”, percebe-se que há: (a) construções com o cuidado de flexionar o verbo com a informação do passado, como: 'Eu falei com um amigo', 'Tani trabalhou ontem', 'Eu estava em aula', e a correta flexão de acordo com a pessoa; (b) construções com adequação ao tempo passado, mas não adequada flexão de pessoa, como em: 'eu fez café da manhã'; (c) construções com o emprego do presente no lugar do passado, por exemplo: 'eu não faz nada'; 'trabalhando'. 
Os casos exemplificados para a construção do futuro, a partir da pergunta "O que você vai fazer amanhã?”, permitem observar: (a) construções em que há uma tentativa de adequação do verbo ao tempo da pergunta, ainda que não ocorra a flexão em pessoa e número, a exemplo de: 'Eu vai fazer amanhã trabalhar'; (b) o adequado uso da perífrase verbal (verbo auxiliar + verbo principal) na construção do verbo ' ir', auxiliar flexionado, mais o verbo principal no infinitivo em 'Vou jogar futebal'; (c) construções no passado como 'eu foi na escola' no lugar de expressões do futuro; e (e) o emprego de sequência de verbos como 'eu vou faço dormir', padrão utilizado na língua nativa dos aprendizes.

Em relação às questões “Do que você não gosta?" e "Do que você mais gosta?" que solicitavam construções expressando o presente, um presente habitual, observou-se que: (a) ocorreram construções com flexão adequada de tempo, número e pessoa como: 'Eu não gosto de levantar cedo' e 'Eu gosto estudar'; e (b) ocorreram construções como 'Eu não gosta de problema' ' 'Eu gosta musca', em que os aprendizes copiaram a forma verbal da questão e, por conta disso, não realizaram a flexão de pessoa adequada - $1^{\underline{a}}$ pessoa do singular.

\section{Considerações finais}

Os pontos levantados neste artigo foram uma tentativa de esclarecer e, assim, compreender, qual a relação entre as línguas $\mathrm{CH}$ e $\mathrm{PB}$ no que se refere à morfologia dos verbos. A partir disso, poderíamos entender, também, as razões das dificuldades que imigrantes haitianos, que estão adquirindo o PB como língua adicional, encontram no uso das construções verbais do PB.

Chegamos à conclusão de que as duas gramáticas usam de diferentes parâmetros para a flexão verbal a partir de um estudo comparativo do uso das formas verbais nas duas línguas, assim como um levantamento de dados de escrita produzidos por alunos haitianos do curso de extensão "Português como língua adicional: fala, escrita e compreensão" realizado na Universidade Tecnológica Federal do Paraná, no Campus Pato Branco. Nossa hipótese foi a de que, dadas às diferenças morfossintáticas do PB, a língua-alvo, e do $\mathrm{CH}$, a língua nativa, aprendizes teriam dificuldade no emprego da flexão dos verbos. 
O PB tem uma complexa morfologia flexional (cf. Câmara Jr., 2017) e os verbos são constituídos de desinências ou morfemas de tempo e modo, de um lado, e morfemas de pessoa e número, de outro. $\mathrm{O} \mathrm{CH}$, por sua vez, é uma língua em que os verbos são invariáveis, isto é, não marcam tempo e modo, nem pessoa e número. Na verdade, as marcas de tempo, modo e aspecto no $\mathrm{CH}$ são realizadas por meio de partículas antepostas ao verbo, sendo, nesse sentido, a gramática dessa língua diferente se comparada à gramática do PB.

Os dados das produções escritas dos imigrantes haitianos, utilizados neste estudo com o propósito de embasar as discussões teóricas com respeito à comparação das línguas, indicam que os aprendizes apresentam, de fato, dificuldades no uso da morfologia verbal do PB. Especificamente, devido ao fato de o $\mathrm{CH}$ não atrelar desinências de modo-tempo e de número-pessoa ao vocábulo verbal, e sim partículas externas e antepostas.

Em suma, as diferenças de marcação de tempo, modo, pessoa e número entre o $\mathrm{CH}$ e o $\mathrm{PB}$, ou seja, diferenças de parâmetros morfossintáticos entre as duas línguas, fazem com que os aprendizes, baseando-se nos padrões de sua língua, produzam formas verbais “inadequadas” no que diz respeito à morfologia verbal. Aspecto corroborado por dados em que não há o emprego da flexão por tempo, pessoa ou número, como: 'Eu vai fazer amanhã trabalhar', 'eu foi na escola' e 'trabalhando'.

Por fim, a partir da compreensão da necessidade e da importância de políticas linguísticas que possam promover a prática do acolhimento a públicos migratórios como os haitianos, dado o crescente movimento migratório no Brasil, este artigo também teve a intenção de contribuir com o conhecimento dos parâmetros morfossintáticos do uso dos verbos no $\mathrm{CH}$, em comparação ao $\mathrm{PB}$, para facilitar o trabalho pedagógico no ensinoaprendizagem desta língua para os haitianos nos cursos de português para estrangeiros. Esse conhecimento pode ser utilizado pelo professor para entender o porquê das dificuldades apresentadas pelos aprendizes em relação à morfologia verbal do $\mathrm{PB}$, e também como instrumento para ajudá-los a transpor essas dificuldades.

\section{Referências}


ALKMIN, T. Sociolinguística: parte I. In.: MUSSALIM, F; BENTES, A. C. Introdução à Linguística 1. São Paulo: Cortez, 2008.

BENTOLILA, A. Marques aspecto-temporelles en créole haïtien: de l'analyse synchronique à la formulation d'hypothèses diachroniques. La Linguistique. n. 23, p. 103-122. 1987.

BENVENISTE, E. Problemas de Linguística Geral. São Paulo: Editora Nacional /EDUSP, 1976.

BOUDREAUX, I. Is French a Creole Language? (Dissertation) Baylor University, Waco: Texas, 2014 .

CÂMARA JR., J. M. Estrutura da língua portuguesa. Petrópolis: Vozes, 2017.

DEGRAFF, M. Kreyòl Ayisien, or Haitian Creole ('Creole French’). In: HOLM, J.; PATRICK, P. L. (Eds.). Comparative Creole Syntax: Parallel Outlines of 18 Creole Grammars. London: Battlebridge Publications, p. $101-126,2007$.

DEGRAFF, M. Morphology and Word Order in "Creolization" and Beyond. In: CINQUE, G.; KAYNE, R. (Eds.) The Oxford Handbook of Comparative Syntax. New York: Oxford University Press. 2008.

ILARI, R; BASSO, R. M. Verbo. In.: ILARI, R. MOURA NEVES, M. H. (Org.) Gramática do português culto falado no Brasil. Volume 2.Campinas: UNICAMP, 2008.

LEFEBVRE, C. Functional Categories in Tree Atlantic Creoles: Saramaccan, Haitian and Papiamentu. Université du Québec à Montréal. 2015.

LEFEBVRE, C. Creole Genesis and the Acquisition of Grammar: the case of Haitian Creole. Cambridge university press. 2006.

LIMA, R. Gramática Normativa da Língua Portuguesa. Rio de Janeiro: José Olympio, 2003.

MAIA, J. D. Gramática: teoria e exercícios. São Paulo: Ática, 1995.

MARGOTTI, F. W. MARGOTTI, R.C. M. F. Morfologia do Português. Florianópolis: LLV/CCE/UFSC, 2009.

PARSONS, T. Thematic relations and arguments. Linguistic Inquiry, n. 26, 1995.

SPEARS, A. Introduction: The Haitian Creole language. In.: SPERAS, A.; JOSEPH, C. The Haitian Creole language: history, structure, use, and education. Lanham, MD: Lexington Books, 2010.

VALDMAN, A. Pidgin and creole linguistics. London: Indiana University Press, 1977.

VALDMAN, A. Diglossia and language conflict in Haiti. International Journal of the Sociology of Language. n. 71, p. 67-80. 1988.

\footnotetext{
* Professora Adjunta do Departamento de Letras da Universidade Federal de Mato Grosso do Sul, campus Aquidauana.

** Professora Adjunta do Departamento de Letras da Universidade Tecnológica Federal do Paraná, campus Pato Branco.
} 